microbiological engineering. The chief two aims of the Centre are : first, to provide facilities for rescarch workers to become acquainted with the different methods of chemical microbiology, by working in one of the research units; and second, to make accessible for scientific investigations substances of microbial origin the isolation of which requires equipment of industrial dimensions not normally available in university laboratories. This Centre will be the forerunner of a number of others which the World Health Organization intends to set up in other parts of the world on a wide basis of co-ordinated research, and for which a number of fellowships are being financed. The realization of this project is an interesting example of the value of the schemes organized by the British Council for British men of science to visit foreign countries. In this case the project was the result of a lecture tour which Prof. Chain undertook in Italy for the British Council in 1947.

\section{Losses from Plant Diseases}

There is, perhaps, a general reticence about the writing of papers which deal with losses from crop disease, yet, whenever dispassionate surveys are made, much useful information of a practical nature is obtained. Mr. W. C. Moore chose to speak on "The Significance of Plant Diseases in Great Britain" for his presidential address to the Association of Applied Biologists (Ann. App. Biol., 36, No. 3, 295 ; 1949). Mr. Moore is head of the Plant Pathology Laboratory of the Ministry of Agriculture, Harpenden, and is therefore in a good position to digest the numerous reports on disease prepared by advisory officers. About a thousand different plant diseases are known in Great Britain, but fortunately only about forty are regarded as of economic importance. Some maladies, such as crown rust of oats, Puccinia coronata, white root rot of many plants, Rosellinia necatrix, and antirrhinum rust, Puccinia antirrhini, are much more serious in southern Britain than in the north. Take-all of cereals, Ophiobolus graminis, chocolate spot of beans, Botrytis sp., and Didymella stem rot of tomato are only severe in certain years. Looking to the future, Mr. Moore considers that gangrene of potato, Phoma foveata, leaf blotch of onion, Heterosporium allii, altemaria blight of tomato, A. solani, and ink disease of iris, Mystrosporium adustum, may well become more troublesome than in the past. He has, indeed, shown how Sclerotium tuliparum, the cause of grey bulb rot of tulips, has increased in distribution since 1922. The status of many other diseases is discussed, and the paper should lead students of plant pathology to that most important asset for their subject-a sense of proportion in assessing disease damage.

\section{Optical Properties of Solid Thin Films}

AN international colloquium on the optical properties of solid thin films was held at Marseilles in April 1949 under the auspices of the Centre National de la Recherche Scientifique (see Nature, 163, 885; 1949), and the full text of the thirty-five papers presented, together with a short foreword by Prof. P. Rouard and a list of those who were invited to participate in the colloquium, is now available and appears in the July issue of the Journal de Physigue et le Radium $(11,305 ; 1950)$. The national representatives who were invited were as follows: Dr. B. H. Billings, Mr. N. W. Scott, Prof. J. Strong and Dr. A. F. Turner (United States) ; Drs. K. M. Greenland, O. S. Heavens and H. Kuhn, and Prof. S.
Tolansky (Great Britain); Drs. B. S. Blaise and P. van Alphen (The Netherlands); Dr. L. Ballerini and Prof. F. Scaldone (Italy); Dr. Schaetti (Switzerland); and Prof. A. Vašicek (Czechoslovakia). The papers are grouped together under five headings: theoretical investigations of the optical properties of thin films; the preparation of films, and various techniques; experimental investigations of the optical properties ; applications ; and bibliography. This last group consists of one paper by P. Cotton and $P$. Rouard, in which an excellent comprehensive survey is given of the literature on the subject of optical thin films and to which is appended some 250 references. Several of the papers are in English; these have French summaries. The remainder are in French, and the majority have English summaries. It is pleasant to note that each paper commences on a separate page. As Prof. Rouard remarks in his foreword, the work described will be of interest to others besides specialists, and shows clearly that French physicists, in addition to those of other countries, have made and are makjng important contributions in this important and rapidly growing field.

\section{New Tension Meter for Wires and Threads}

The Saxl Instrument Co., Harvard, Mass., has recently announced the development of a new and improved model of tension meter with a total capacity of 125 grams. This meter has applications not only in the textile field but also in the electrical field, wherever quick tension measurements on wires, filaments, thread, etc., are required. The new model has twice the sensitivity of the old $250 \mathrm{gm}$. model which is still being manufactured. In addition to instant trigger action and correct dynamical calibration under performance conditions, the meter is equipped with ball-bearings throughout, thus reducing roller friction to negligible dimensions. Special precision pulleys recessed in the trigger mechanism automatically guide the yarn into position, and gentle insertion and release are assured. For sensitive nylons and other fine yarn the first revolution of the dial, giving readings on black figures up to 50 gm., suffices. The remaining part of the range, 50-125 gm., is read from red figures on the second revolution of the dial. Therefore, without special adjustments, the pointer can overtravel and continue to give precise readings even when the tension is above the $50 \mathrm{-gm}$. range.

\section{Technology of a Modern Stone-Age People in New Guinea}

THE methods used by prehistoric man to fashion his stone and bone implements have long been an object of speculation. Not all tools are chipped in the same way, and more than one way of shaping bone objects can be observed. While analogies must never be pressed too far, it is always interesting to know how a modern stone-age folk set about similar tasks. This is described in "The Technology of a Modern Stone Age People in Now Guinea", by Beatrice Blackwood, a publication of the University of Oxford Pitt Rivers Museum (Occasional Papers on Technology, 3; pp. $60+17$ pl. ; $1950 ; 10 s .6 d$.$) .$ The author has lived many months in New Guinea, and the volume is the result of careful observation on the spot of the various techniques employed. The making of stone-bladed adzes, stone-headed clubs, wooden clubs, bows and arrows, bamboo knives, and bark cloth, and also fire-making are all described 